\title{
Human Activity and Forest Degradation Threaten Populations of the Nigeria-Cameroon Chimpanzee (Pan troglodytes ellioti) in Western Cameroon
}

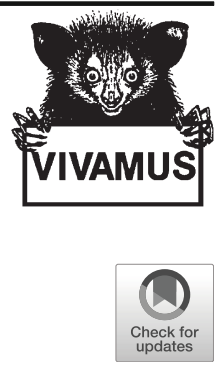

\section{Chefor Fotang, et al. [full author details at the end of the article]}

Received: 18 May 2020 / Accepted: 26 November 2020/Published online: 19 February 2021

(C) The Author(s) 2021

\begin{abstract}
Increased human activities such as commodity-led deforestation, extension of agriculture, urbanization, and wildfires are major drivers of forest loss worldwide. In Cameroon, these activities cause a loss of suitable primate habitat and could ultimately threaten the survival of chimpanzees (Pan troglodytes). We derived independent estimates of the population size of the Endangered Nigeria-Cameroon chimpanzee (Pan troglodytes ellioti) in Kom-Wum Forest Reserve, Cameroon, and surrounding unprotected forest areas through 1) direct observations, 2) camera trapping, 3) distance sampling, 4) marked nest counts, and 5) standing crop nest counts. In addition, we georeferenced signs of chimpanzee and human activity along line transects. We used a generalized linear mixed model to predict the occurrence of chimpanzees in response to edge length (measured as the perimeter of core forest patches), core area of forest patches (measured as area of forest patches beyond an edge width of $100 \mathrm{~m}$ ), habitat perforation (measured as the perimeter of nonforested landscape within core forest patches), patch size(measured as area of forest patches), and forest cover. Chimpanzee density estimates ranged from 0.1 (direct observation) to 0.9 (distance sampling) individuals $\mathrm{km}^{-2}$ depending on estimation method with a mean nest group size of 7 \pm 5.4 (SD). The mean encounter rate for signs of chimpanzee activity was significantly

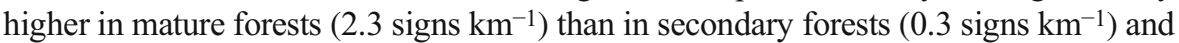
above $1000 \mathrm{~m}$ elevation $\left(4.0\right.$ signs km$\left.{ }^{-1}\right)$ than below $1000 \mathrm{~m}\left(1.0\right.$ signs km$\left.{ }^{-1}\right)$. The mean encounter rate for signs of human activity was significantly higher in secondary (8.0 signs $\left.\mathrm{km}^{-1}\right)$ than in mature forests $\left(0.9\right.$ signs $\left.\mathrm{km}^{-1}\right)$. Secondary forests, habitat perforation, and edge length had a significant negative effect on the occurrence of chimpanzee signs. Overall, human activity and forest degradation affected the number of observed chimpanzee signs negatively. Regular antipoaching patrols and reforestation programs in degraded areas could potentially reduce threats to populations of endangered species and may increase suitable habitat area.
\end{abstract}

Keywords Bushmeat hunting · Core areas · Edge length · Forest fragmentation · Forest perforation $\cdot$ Nest counts $\cdot$ Mature forest $\cdot$ Pan troglodytes ellioti $\cdot$ Secondary forest

Handling Editor: Joanna Setchell 


\section{Introduction}

Increasing human activities such as commodity-led deforestation, extension of agriculture, urbanization, and wildfires are major drivers of forest loss worldwide (Curtis et al. 2018). These activities cause habitat loss, fragmentation, and destruction of natural ecosystems (Estrada et al. 2017; Haddad et al. 2015). The effects of forest fragmentation include decreasing patch sizes (larger number of smaller patches), increased edge effects (more fragmented landscapes contain more edge for a given amount of habitat), and patch isolation (distance from a patch to its neighbouring habitats; Fahrig 2003). The loss of forest area and isolation of forest fragments can lead to a decrease in the abundance of animal and plant species (Arroyo-Rodríguez and Mandujano 2006; Estrada et al. 1999). Forest mammals and primates in particular are vulnerable to the effects of forest fragmentation (Arroyo-Rodríguez and Mandujano 2006; Chapman and Peres 2001). While some studies have reported a negative effect of habitat fragmentation on primates (Arroyo-Rodríguez and Dias 2010; Estrada and Coates-Estrada 1996; Estrada et al. 1999), others have reported higher densities of primates in small forest fragments (González-Solís et al. 2001), and some have indicated no changes in primate density between forest edge and interior (Bolt et al. 2018). Although some primates show flexibility in human dominated landscapes (McLennan et al. 2017), habitat loss and degradation have resulted in a decline of about $75 \%$ of the world's primate species, of which $60 \%$ are endangered (Estrada et al. 2017, 2019). This situation makes it crucial to measure threats to primate populations by determining the population status and trends in density and distribution (Kühl et al. 2008).

Like populations of many other primate species, populations of chimpanzees (Pan troglodytes) throughout Africa have declined due to habitat loss, habitat degradation, poaching, and disease (Humle et al. 2016; Walsh et al. 2003). These activities are major threats to the rarest and least studied chimpanzee subspecies (Morgan et al. 2011), the Nigeria-Cameroon chimpanzee, of which ca. 3500 individuals remain in the wild (Morgan et al. 2011). In southwestern Nigeria, agricultural activity, timber extraction, and hunting are major threats to populations of chimpanzees (Ogunjemite and Dansu 2014). In the Littoral and Southwest regions of Cameroon, the expansion of oil palm plantation and human population density is associated with permanent destruction of chimpanzee habitat (Morgan et al. 2011). The loss of chimpanzee habitat in central Cameroon is driven by uncontrolled burning by cattle grazing herdsmen (Morgan et al. 2011). Illegal timber exploitation, farming, hunting, bush fires, and advancing pastures are major threats to chimpanzee survival in northwest Cameroon (Doumbé 2014; Morgan et al. 2011). Unlike in the Congo Basin south of the Sanaga River, which is characterized by lowland rainforests, the range of chimpanzees in the Gulf of Guinea is characterized by mountainous rainforest habitat (Abwe et al. 2019; Sesink Clee et al. 2015). Forest type and anthropogenic disturbance influence nest site location (Koops et al. 2012; Last and Muh 2013). Chimpanzees tend to build their nests in mature forest vegetation (Kamgang et al. 2018), in areas with a low degree of human pressure (Last and Muh 2013; Njukang et al. 2019) and at high elevations (Njukang et al. 2019).

The current population estimates for the Nigeria-Cameroon chimpanzee are problematic (Hughes et al. 2011), but suggest 1500 chimpanzees survive in Nigeria (Hughes et al. 2011), with the largest population of 900-1000 individuals found in 
Gashaka-Gumti National Park, Nigeria (Sommer et al. 2004). Ngel Nyaki Forest Reserve is home to 12-16 chimpanzees (Beck and Chapman 2008; Dutton 2012) and $c a .400$ chimpanzees may survive in Okwango Division of Cross River National Park (McManus 2005). From 3000 to 4000 individuals remain in Cameroon (Morgan et al. 2011), split into two distinct genetic pools that occupy ecologically and environmentally distinct habitats in mountainous rainforest in western Cameroon and forestwoodland-savanna mosaic in central Cameroon (Abwe et al. 2019; Mitchell et al. 2015; Sesink Clee et al. 2015). Strongholds for chimpanzees in Cameroon include Ebo forest, with 626-1480 individuals (Ndimbe et al. 2016), Mbam and Djerem National Park with more than 500 individuals (Greengrass and Maisels 2007; Kamgang et al. 2018; Maisels et al. 2009), and Banyang-Mbo Wildlife Sanctuary with 800-1450 individuals (Greengrass and Maisels 2007). Tubah-Awing Forest and Kom-Wum Forest Reserve in the Northwest Region also harbor chimpanzees and have been proposed as a multisite protected area, affording appropriate legal status for the remaining wildlife and forest resources (Morgan et al. 2011). As indicated by the publication dates, several of these estimates may be outdated.

In the past two decades, research and conservation efforts for chimpanzees have focused on populations in continuous forests such as Gashaka Gumti National Park (Fowler and Sommer 2007; Sommer et al. 2004), Ebo forest (Abwe et al. 2019, 2020; Abwe and Morgan 2008), Lebialem complexBanyang Mbo (Greengrass and Maisels 2007), Mbam \& Djerem National Park (Abwe et al. 2019, 2020; Kamgang et al. 2018), and forests northwest of the Sanaga River and Takamanda-Mone-Mbulu (Funwi-Gabga et al. 2014). Only recently have some populations in fragmented habitats received attention in Ngel Nyaki Forest Reserve in Nigeria (Beck and Chapman 2008; Dutton 2012; Dutton and Chapman 2015a, b; Dutton et al. 2016; Knight et al. 2016), Babanki-Finge Forest (Doumbé 2014), Fungom Forest Reserve, and Kom-Wum Forest Reserve in Cameroon (Chuo et al. 2017; Doumbé 2015; Fotang 2018).

The IUCN-endorsed regional conservation action plan for chimpanzees outlined measures and strategies to prevent further population decline (Morgan et al. 2011). Kom-Wum Forest Reserve is described as a priority conservation site in the plan with a focus on surveys to confirm chimpanzee presence and estimate population size (Morgan et al. 2011). An initial survey in Kom-Wum Forest Reserve used trails made by local people to access the reserve and found 458 chimpanzee nests (Doumbé 2015). A subsequent survey used the reconnaissance method to estimate chimpanzee abundance and anthropogenic activities and found 11.3 chimpanzee signs per $\mathrm{km}$ and 1.19 anthropogenic signs per km (Chuo et al. 2017). The main objectives of our study were to 1) determine the population size of chimpanzees in Kom-Wum Forest Reserve and surrounding forests using five independent methods, 2) understand habitat preferences in relation to forest type (mature vs. secondary forest) and elevation (above and below 1000 m, following Koops et al. 2012 and close to midpoint for the study area) in the study area, and 3) investigate the effect of human activity on the relative density of chimpanzees in the study area. We hypothesized that human activities and forest degradation reduce chimpanzee abundance (Bryson-Morrison et al. 2017; Morgan et al. 2018). Thus, we predicted that the encounter rate of chimpanzee signs is lower in secondary than in mature forests, that the encounter rate for chimpanzee signs is higher in the reserve than surrounding forest that are subject to more anthropogenic 
pressure, and that parts of the reserve with higher elevation would have more chimpanzee signs compared to those with lower elevation.

\section{Methods}

\section{Study Area}

Kom-Wum Forest Reserve was created in 1951 and spans two administrative units: Boyo and Menchum Divisions in the northwest of Cameroon (Fig. 1a; latitude $6^{\circ} 9^{\prime}$ $39.47^{\prime \prime} \mathrm{N}$ and longitude $10^{\circ} 13^{\prime} 9.16^{\prime \prime} \mathrm{E}$ to latitude $6^{\circ} 19^{\prime} 39.42^{\prime \prime} \mathrm{N}$ and longitude $10^{\circ} 13^{\prime}$ $3.93 ")$. Extending to 565-1640 $\mathrm{m}$ above sea level in elevation (Fig. 1c), the $80 \mathrm{~km}^{2}$ Kom-Wum Forest Reserve is covered by submontane tropical forest that spreads over an undulating and picturesque landscape (Sunderland and Mannaseh 2003). The temperature ranges from $15^{\circ} \mathrm{C}$ to $38^{\circ} \mathrm{C}$ with a mean yearly rainfall of $\mathrm{ca} .2400 \mathrm{~mm}$ and humidity of $82 \%$ (PNDP 2011). The area has two distinct seasons, a wet season (mid-March to mid-October) and a dry season (mid-October to mid-March).

In addition to chimpanzees, Kom-Wum Forest Reserve harbours six diurnal and six nocturnal primate species (Chuo et al. 2017; Doumbé 2015; Fotang 2018). Among these species, two are endangered (EN) and 11 are least concern (LC). The diurnal monkey species include putty-nosed monkey (Cercopithecus nictitans ludio, LC), mona monkey (Cercopithecus mona, LC), olive baboon (Papio anubis, LC), tantalus monkey (Chlorocebus tantalus, LC), patas monkey (Erythrocebus patas, LC), and Preuss's monkey (Allochrocebus preussi, EN). The nocturnal primate species are Thomas's dwarf galago (Galagoides thomasi, LC), Demidoff's dwarf galago (Galagoides demidoff, LC), Northern needleclawed galago (Euoticus pallidus, LC) and Allen's galago (Sciurocheirus alleni, LC), Milne-Edward's potto (Perodicticus edwardsi, LC), and Calibar angwantibo (Arctocebus calabarensis, LC), which are protected entirely in Cameroon and restricted to West Cameroon and East Nigeria (Doumbé 2015). The presence of some mammals (red duiker [Cephalophus dorsalis, LC], bushbuck [Tragelaphus scriptus, LC], red river hogs [Potamochoerus porcus, LC], and white-bellied pangolin [Phataginus tricuspis, EN]) and birds (Bannerman's turaco [Tauraco bannermani, EN], blue turaco [Corythaeola cristata, LC], and blackcasqued wattled hornbill [Ceratogymna atrata, LC)]) have been verified (Fotang 2018).

Kom-Wum Forest Reserve encompasses the village communities of Mughom and Bueni in the south and borders the village communities of Bu, Mbengkas, Baiso, and Mbongkissu (Fig. 1b and c). These local communities rely on forest resources for their livelihood (Kah 2015).

\section{Sampling}

Satellite Images and Digital Elevation Models We obtained a satellite image (Landsat 8, $30 \mathrm{~m}$ pixel) for February 9, 2017 from the United States Geological Survey to produce a land cover map of the study area. We derived the elevation of the study zone from a Shuttle Radar Topography Mission $30 \mathrm{~m}$ resolution Digital Elevation Model and superimposed this on the land cover map (Fig. 1c). We classified land cover as 

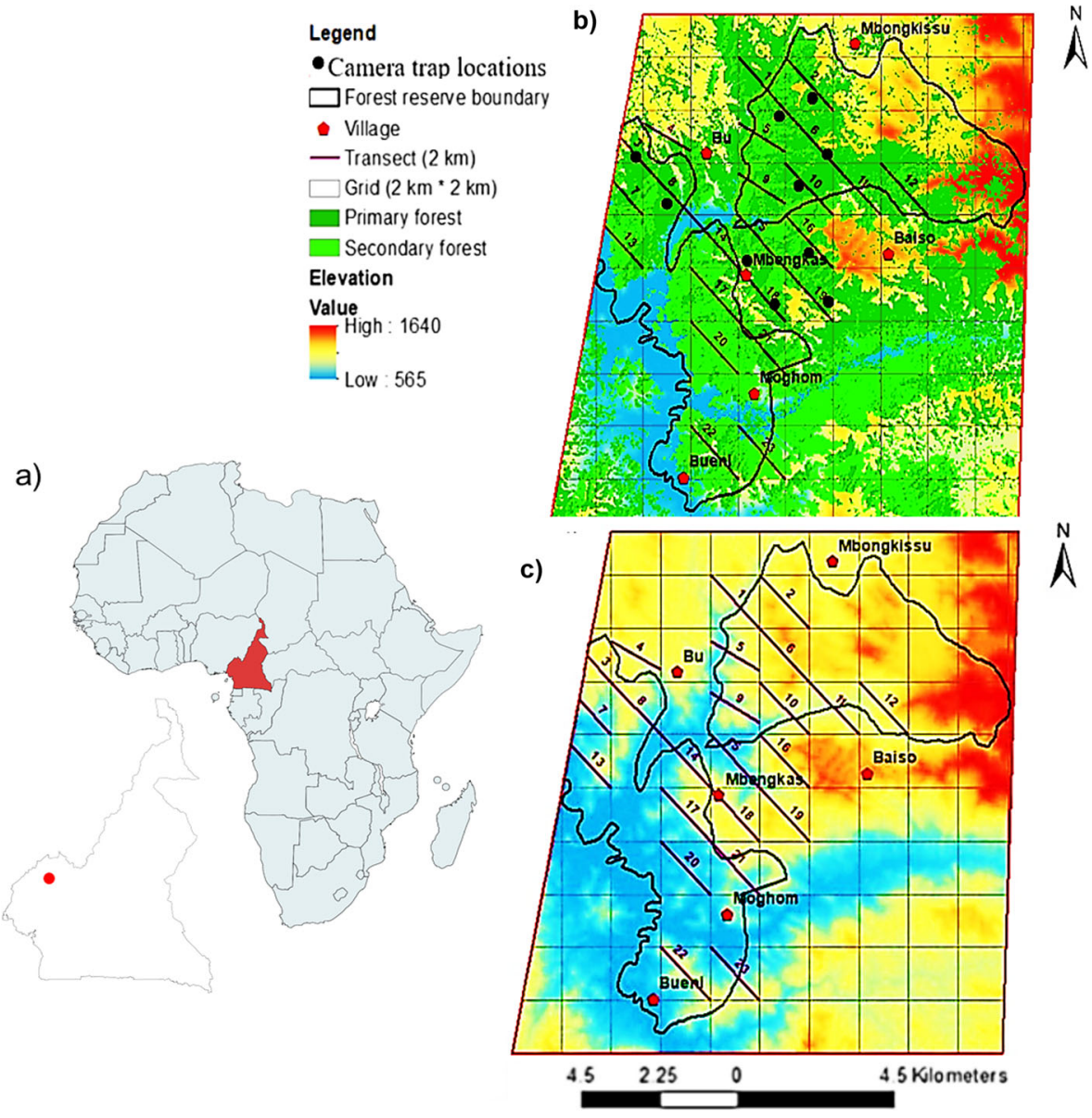

Fig. 1 Maps of (a) Cameroon and the study location Kom-Wum Forest Reserve in northwest Cameroon (red point), (b) Kom-Wum Forest Reserve including major villages with line transects for surveys (1-23) and location of camera traps, and (c) line transects and elevation (May 15 to September 23, 2018).

mature forest, secondary forest, grassland, and water bodies using supervised classification and the maximum likelihood algorithm in ArcGIS version 10.6 (Ganasri and Dwarakish 2015) as recommended in Enoguanbhor et al. (2019). We imported the land cover types to the Landscape Fragmentation Tool in ArcGis (Vogt et al. 2007). We included mature and secondary forests in the forest class and grassland and water bodies in the nonforest class (Vogt et al. 2007). We used an edge-width of $100 \mathrm{~m}$ to further classify forest into edge, core, perforated, and patch (Vogt et al. 2007). We generated georeferenced square plots $2 \mathrm{~km} \times 2 \mathrm{~km}$ in ArcGIS 10.6.1 and superimposed them on satellite images of the study zone (Fig. 1b). For each square we calculated percentage forest cover, edge length, core area of forest patches, patch size, and forest perforation using the geometric landscape tool in ArcGIS. We measured edge length as the perimeter of core forest patches, core area of forest patches as forest area beyond the edge width of $100 \mathrm{~m}$, perforated as the perimeter of nonforested landscape within core forest patches, and patch size as area of forest patches. We used data collected during 
the survey (May-September 2018) to confirm the Geographical Information System Classification as recommended by Congalton (1991).

Survey Techniques and Design We conducted fieldwork between 15 May and 23 September 2018 using 1) direct observation, 2) camera trapping, 3) distance sampling, 4) marked nest count, and 5) standing crop nest count. We chose this integrated approach to overcome the known limitations of single methods (Howe et al. 2017). We selected the nest count method based on the fact that chimpanzees in Kom-Wum Forest Reserve were not habituated and thus were extremely difficult to observe in the wild (Plumptre and Reynolds 1996). We used camera trapping to increase the probability of detecting chimpanzees (Rovero and de Luca 2007; Rovero et al. 2010). We established line transects following a recce-transect survey conducted in this area (Chuo et al. 2017). We sampled the georeferenced square grids of $2 \mathrm{~km} \times 2 \mathrm{~km}$ with transects. In total, we superimposed 23 systematic, equally spaced $(1000 \mathrm{~m})$ line transects (each $2 \mathrm{~km}$ long with a random start) across 23 grids $\left(92 \mathrm{~km}^{2}\right)$ in the study zone (Buckland et al. 2001). We generated the starting point of each transect using a random number table. We oriented line transects in the northwest-southeast direction perpendicular to three rivers that flow through the reserve. We considered transects in grids at the border as inside the reserve if the surface area of the grid within the reserve boundaries was $\geq 50 \%$ of the surface area of a full grid cell. We surveyed all transects assuming that we detected chimpanzee nests on the transect line with certainty, and that we measured distances from the center of the nest to the line transect correctly (Buckland et al. 2001).

In the field, we identified the starting point of each predetermined line transect from the land cover map and the position of wildlife cameras using a GARMIN GPSMAP 64s device. We installed one LTL-5310A Acorn wildlife camera in each of 10 grids that contained at least one chimpanzee nest group along frequently used chimpanzee paths and feeding or tool use sites (Fig. 1b). We programmed cameras to operate $24 \mathrm{~h}$ a day and to take one photograph and then continue taking a video for $60 \mathrm{~s}$ at a resolution of 1080 pixels at a height $30-80 \mathrm{~cm}$ above the ground. The survey team checked camera traps to replace SD cards and batteries during transect visits. We left camera traps at their locations if a chimpanzee was photographed and moved them to a new position if no images of a chimpanzee were obtained (Rovero et al. 2010). We replaced defective cameras that contained pictures of chimpanzees in two grids with functional cameras from two grids that did not photograph chimpanzees.

We recorded signs of chimpanzee presence during transect surveys, including nests, sightings, vocalizations, feeding signs, footprints, feces, and tool use sites (Fig. 2a). We recorded signs of human-related activity including hunting, farming, logging, livestock grazing, and collection of nontimber forest products (Fig. 2b). In the survey, we defined a nest as a structure with visible twigs that appear to be broken or bent inwards by chimpanzees (Tutin and Fernandez 1984). We distinguished arboreal (night or day) and ground (night or day) nests (Fig. 3). We considered a nest as "arboreal night" if it was elaborately constructed, with a circular thick cushion-like support, and sometimes with feces beneath and as "arboreal day" if it was poorly constructed, with weak-cushioning support (Fruth and Hohmann 1996). We considered nests as "ground night" if they were well constructed, contained chimpanzee hair, and were in the vicinity of other arboreal nests (Furuichi and Hashimoto 2000; Koops et al. 2007). Ground day nests were simple weak cushion-like constructions made up of an assemblage of leaves that 
contained chimpanzee hair (Boesch 1995). We assumed all nests we encountered during the survey were constructed by chimpanzees because gorillas do not occur in this forest (Chuo et al. 2017; Doumbé 2015).

We defined nest age following Tutin and Fernandez (1984). We considered nests of the same age class within a radius of $50 \mathrm{~m}$ of each other as belonging to the same group (White and Edwards 2000). We recorded the GPS location, nest group size, perpendicular distance to the transect, and age class of nest for all nests. We classified vegetation type as mature forest, old secondary forest, or grassland (White and Edwards 2000). Mature forest consisted of mixed forest with many large trees, high canopy cover, and sparse vegetation cover on the ground, consisting mostly of shrubs

Legend

$\square$ Forest reserve boundary
Village
$\square$ Transect ( $2 \mathrm{~km}$ )
$\square$ Encounter rate classes
$\square 0.0$
$\square 0.1 \cdot 0.9$
$\square 1.0 \cdot 1.9$
$\square 3.0 \cdot 3.9$
$5.0 \cdot 5.9$
$\square 6.0$
$\square$ Grid (2 km * $2 \mathrm{~km}$ )
$\square$ Primary forest
$\square$ Secondary forest
Elevation
Value
High : 1640
. Low : 565

Legend

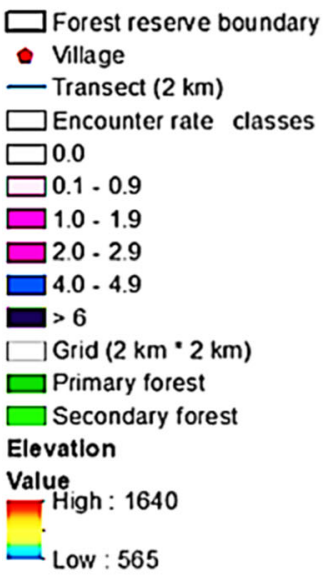

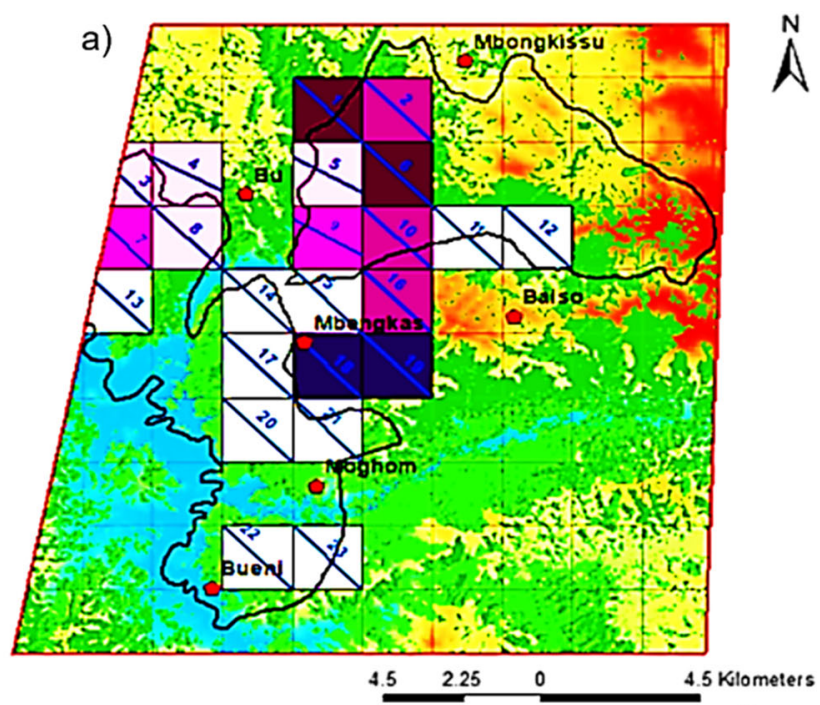

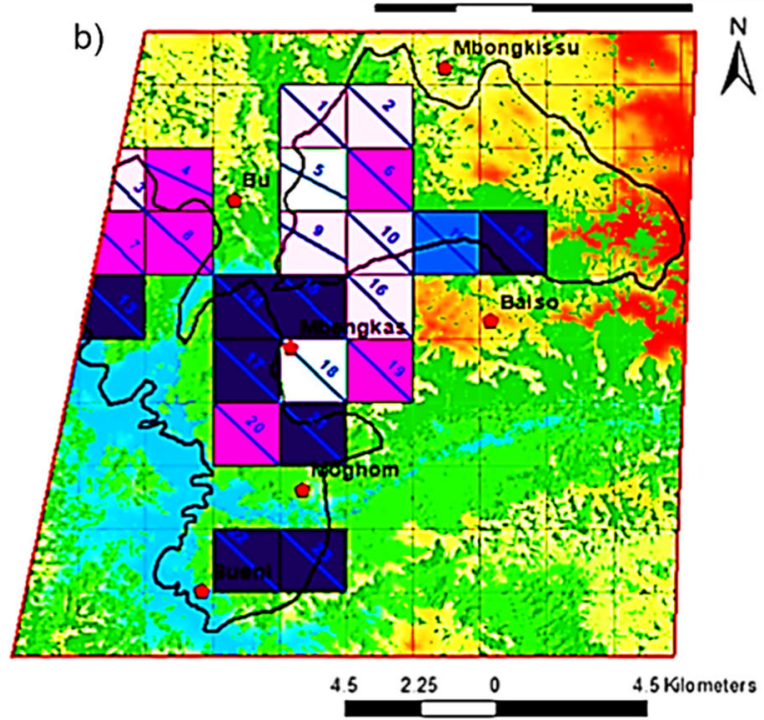

Fig. 2 Encounter rate classes for signs of (a) chimpanzee and (b) human activity during a survey in KomWum Forest Reserve, Cameroon (May 15-September 23, 2018). 


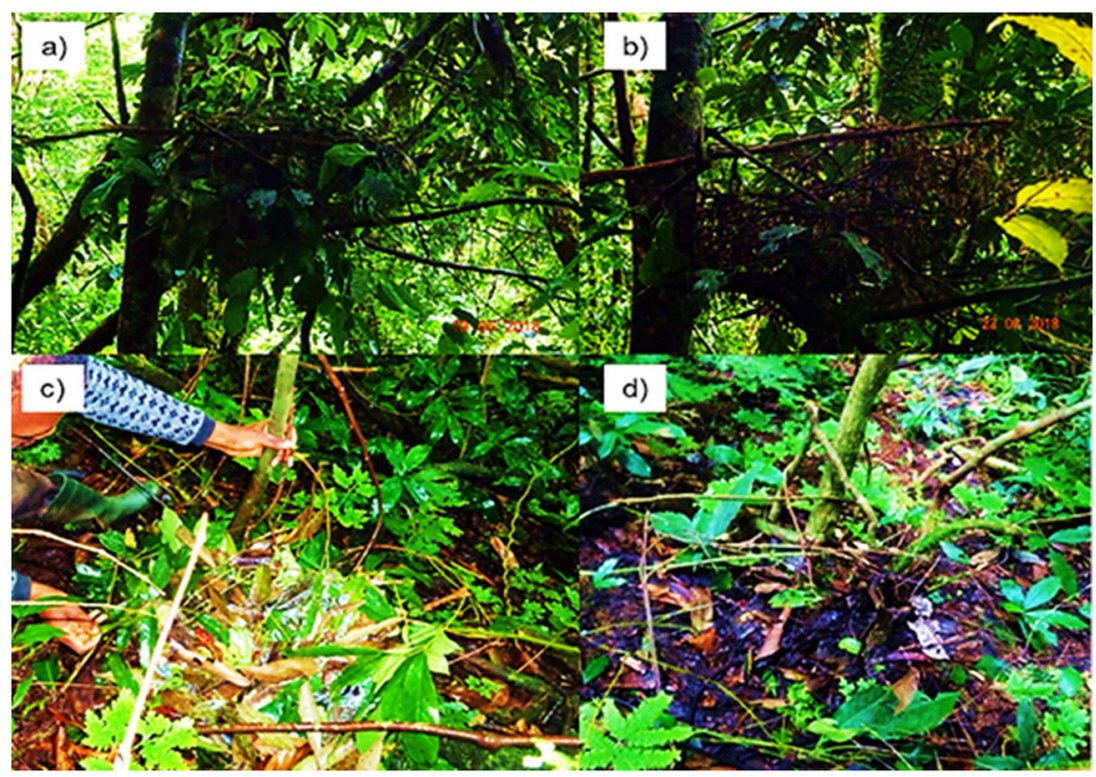

Fig. 3 Stages of deterioration in nests made by chimpanzees. a New arboreal nest ( $0-16$ days). b Old arboreal nest (83-91 days). c New ground nest (0-3 days). d Old ground nest (30-75 days) in Kom-Wum Forest Reserve, Cameroon ( May 15-September 23, 2018).

and mixed forest, with understory dominated by lianas and Marantaceae. Old secondary forest included areas with large trees but showing evidence of disturbance by humans, absence of food crops, with occasional oil palm or mango trees. Grassland was grazing land characterized by short-grass mixed with arable fields and cattle paths. We assessed the area covered by each vegetation type along line transects using a hip chain distance measurer.

Monitoring Nests and Deterioration Rates Based on the results of the first survey, we revisited 13 transects with at least one chimpanzee nest group. We revisited transects approximately every 16 days to establish nest decay rate. We considered new nests encountered during revisits as constructed between transect walks (Plumptre and Reynolds 1996). We tagged and revisited all observed nests in the first survey of line transects to evaluate their deterioration. We considered nests as fully decayed when the nest frame had completely disappeared, the branches could no longer be recognized, and branches did not appear to be broken or bent by chimpanzees (Kouakou et al. 2009; Tutin and Fernandez 1984). Overall, we surveyed 13 transects 5 times (130 km) and 10 transects once $(20 \mathrm{~km})$, giving an effective effort of $150 \mathrm{~km}$ (Electronic Supplementary Material [ESM] Tables SI, SII, and SIII).

\section{Statistical Analysis}

We used Distance 7.0 (Thomas et al. 2010) and R studio version 3.5.1 for statistical analysis (Venables et al. 2008). We checked the normality of residuals with the Shapiro-Wilk normality test and homogeneity of variances using the Levene test. 
We compared encounter rates of chimpanzee and human activity signs between forest type (mature versus secondary forest), elevation (above vs. below $1000 \mathrm{~m}$ ), and location of transects (inside vs. outside reserve boundaries) based on Cohen's $d$ as a measure of effect size and the Wilcoxon rank-sum test (Ho et al. 2019). We used multiple regression (Kim 2019) to test the effect of human activity (logging, farming, grazing, and harvesting of nontimber forest products) on the encounter rate of chimpanzee signs in the reserve. We used a generalized linear mixed-effect regression model (Baayen et al. 2008), with binomial family to predict the effect of edge length, habitat perforation, patch size, and forest covers (mature and secondary forests) on the probability of chimpanzee occurrence. We used locations with signs of chimpanzee presence (direct sightings, nests, dung, or tool use sites) to extract presence pixel values. We produced chimpanzee absence points (background pixel values) using 100 randomly generated points from each grid containing a chimpanzee point. We used Pearson correlation to test the correlation between predictors in regression analyses.

\section{Direct Observations and Camera Trapping}

We based direct observation of chimpanzees on groups, not individuals (Kühl et al. 2008). We estimated the relative abundance index (RAI, Eq. 1) from camera trap data as the number of photographs per 100 trap days (O'Brien et al. 2003). We considered photographs of chimpanzees as independent if the time between two consecutive photographs was longer than $30 \mathrm{~min}$ (O'Brien et al. 2003). We considered photographs with one or more chimpanzee individuals as single independent photographs (Jenks et al. 2011). We defined a trap day as a camera trap installed at a single location for $24 \mathrm{~h}$ and the total number of trap days as the sum of trap days for all camera traps minus the days that cameras were defective or ran out of batteries. We noted the date, time, and number of individuals for each camera event.

The equation for the Relative Abundance Index (RAI) is

$$
\begin{gathered}
\text { RAI }=\left(\frac{\text { Sum of all independent photographs of chimpanzees for all cameras } \times 100}{\text { Total number of camera trap days }(\text { Number of cameras } \times \text { number of days cameras are operational })}\right) \\
\text { RAI }=\left(\frac{9 \times 100}{(5 \times 126)}\right)=1.4 \text { per } 100 \text { days of camera trapping }
\end{gathered}
$$

\section{Density, Distance Sampling, Standing Crop Nest Count, and Marked Nest Count}

We considered all nests $(N=271)$ in standing crop nest count (SCNC) analysis, as it identifies nest decay rate (Plumptre and Reynolds 1996) but only nests encountered during the first transect survey $(N=158)$ for distance sampling analysis. We selected this approach to allow comparison of distance sampling results to previous studies that used the same approach. We used only new nests encountered during the intersurvey period $(N=113)$ for marked nest count (MNC) analysis (Plumptre and Reynolds 1996). We tested several models in distance analyses and considered 
the model with the lowest Akaike information criterion (AIC) as the best model (Buckland et al. 2001). We based the analysis on single nest observations because we encountered fewer nest groups $(N=59)$ than required to provide a reliable estimate in Distance $(N=60)$. We used the effective strip width of all transects (as calculated in distance sampling) to estimate nest density in the SCNC and MNC methods. We converted nest density estimates to density of chimpanzees by applying the formula: $D_{\text {ind }}=N_{\text {all nests }} / 2 L w$ (prt), for SCNC, where $D_{\text {ind }}$ is the number of individual, $N$ is the number of nests observed along transect, $w$ is effective strip width of transect, $L$ is the transect length (in $\mathrm{km}$ ), $p$ is the proportion of nest builders in the population, $r$ is the rate of nest production per individual per day, and $t$ is the nest decay time (Ghiglieri 1984). When using the marked nest count method, the formula becomes $D_{\text {ind }}=N_{\text {newnest }} / 2 L w$ (pri), where $N_{\text {newnest }}$ is the number of new nests (fresh and recent nests) constructed during the intersurvey period, $i$ is the intersurvey period, and the other parameters remain the same as in the SCNC formula (Buckland et al. 2001; Hashimoto 1995; Plumptre and Reynolds 1996). We obtained densities by correcting for factors such as nest decay rate (estimated in this study) for distance sampling and SCNC, the proportion of nest builders in the population (0.83) following Plumptre and Cox (2006) and the nest production rate per individual per day (1.09) following Morgan et al. (2006) and Plumptre and Reynolds (1996). We obtained population sizes by extrapolating chimpanzee density estimates to the total forest area of $92 \mathrm{~km}^{2}$.

\section{Chimpanzee and Human Activity Signs}

We calculated encounter rates (number of observations $/ \mathrm{km}$ ) as the total number of signs encountered $(N)$ divided by the total length of the transect $(L)$ in $\mathrm{km}$ (Mathot and Doucet 2005). We calculated encounter rates for signs of chimpanzee and human activity. We defined encounter rate classes and assigned values for each transect. We imported the encounter rate classes into ArcGIS software (ArcMap 10.6.1, ESRI) and assigned different colour bands to different encounter rate classes (no observation = 0.0 ; few observations $=0.1-2.9$; many observations $>3$ ). Finally, we created spatial distribution maps with different colour bands representing the relative density of chimpanzee and human activity.

\section{Ethical Note}

This research respected the principles for research on nonhuman primates outlined in the American Society of Primatologists manual for the ethical handling of primates. The research permits to conduct this research were obtained from the Ministry of Scientific Research and Innovation in Cameroon. The authors declare that they have no conflict of interest.

Data availability The datasets generated and/or analyzed during the current study are not publicly available in an attempt to protect the species in the study area; however, these can be made available from the corresponding author by reasonable request. 


\section{Results}

\section{Density, Direct Observations, and Camera Trapping}

In total, we counted 271 nests along 23 transects that we surveyed repeatedly over 131 days, for a total survey effort of $150 \mathrm{~km}$. The mean nest group size was $7.0 \pm 5.4$ (SD, range 2-22). We found 22 fresh nests and fresh chimpanzee feces at a single location, suggesting that the chimpanzee group left the site a few minutes prior to the visit and slept in the nests overnight. We sighted chimpanzees five times ( 5 groups, 0.03 groups $\mathrm{km}^{-1}$ ) during the survey and the maximum group size we observed directly was $\geq 10$ individuals. We estimated chimpanzee density at 0.1 individuals $\mathrm{km}^{-2}$ through direct observation, with a maximum group size of 10 chimpanzees in $92 \mathrm{~km}^{2}$ of the forested area. Camera traps obtained nine independent photographs of chimpanzees (Fig. 4). The number of individuals in independent photographs or videos ranged from 2 to 9. The relative abundance index of chimpanzees was 1.4 individuals for 100 days of camera trapping (Eq. 1). The largest photographed group of nine chimpanzees was two adult females each carrying offspring, two weaned juveniles, one adult male, and two adults whose sex we could not determine.

\section{Nest Decay Rates}

We obtained a mean decay time of $101.0 \pm 25.5$ (SD) days and an intersurvey period of 64 days by monitoring 7 ground nests and 28 arboreal nests from the beginning of the study until all nests decayed completely. All 7 ground nests had decayed completely within 75 days while the 28 arboreal nests decayed completely after 126 days (Fig. 3).

\section{Density, Distance Sampling, SCNC, and MNC}

The half-normal + cosine adjustment model gave the best fit in distance sampling with the lowest AIC value. Chimpanzee densities were 0.9 individuals $\mathrm{km}^{-2}$ using distance sampling (Table I). Mean nest densities were $21.1 \mathrm{~km}^{-2}$ for $\mathrm{MNC}$ and $44.0 \mathrm{~km}^{-2} \mathrm{SCNC}$ analysis. When corrected for an intersurvey period of 64 days and nest decay rate of 101 days, chimpanzee densities were $0.4 \mathrm{~km}^{-2}$ for MNC and 0.5 individuals $\mathrm{km}^{-2}$ for SCNC methods (Eqs. 2 and 3). Distance sampling produced the largest nest density per $\mathrm{km}^{-2}$ while $\mathrm{MNC}$ produced the lowest, resulting in large variability in estimated population sizes in Kom-Wum Forest Reserve (Table I).

The MNC equation for transects $1,2,3,5,6,9,10,16,18$, and 19 is

$$
\left(\frac{N_{\text {newnest }}(=113)}{(2 \times w(0.02056) \times L(130)] /[p(=0.83) \times r(=1.09) \times i(=64)]}\right)
$$

$D_{\text {ind. }}=113 / 309.5=0.37$ weaned chimpanzee $\mathrm{km}^{-2}$

The equation for SCNC for all transects is 


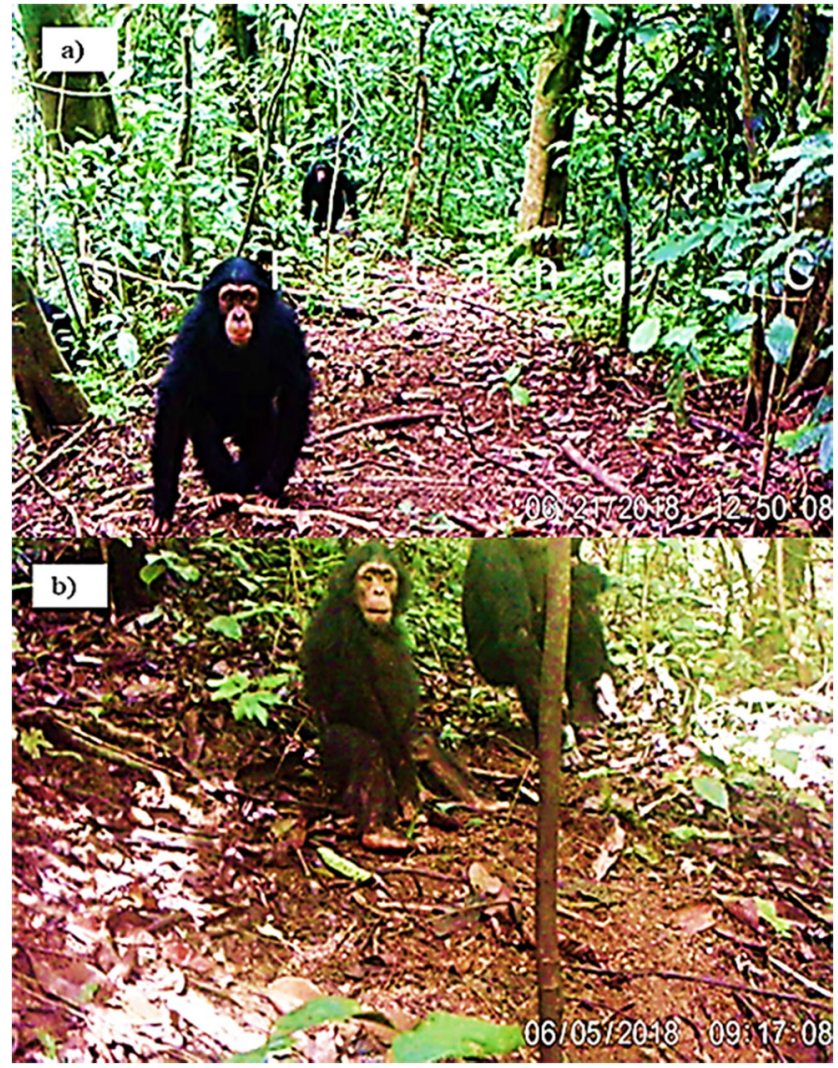

Fig. 4 Chimpanzee in Kom-Wum Forest Reserve, Cameroon, photographed by wildlife cameras with (a) a juvenile leading a group and (b) a juvenile and a nursing adult female (May 15-September 23, 2018).

$$
D_{\text {ind }}=\left(\frac{N(=271)}{(2 \times w(=0.02056) \times L(=150)][p(=0.83) \times r(=1.09) \times t(=101)]}\right)
$$

$D_{\text {ind. }}=271 / 563.6=0.48$ weaned chimpanzee $\mathrm{km}^{-2}$

\section{Chimpanzee Activity Signs}

In total, we encountered 405 signs of chimpanzee activity along the 23 transects resulting in 2.7 signs $\mathrm{km}^{-1}$. Nests $(N=271)$ were the most common signs followed by food remains $(N=68)$, feces $(N=35)$, vocalizations $(N=26)$, and tool use sites $(N=5)$. The mean encounter rate of chimpanzee signs was significantly higher in mature $\left(2.27 \pm \mathrm{SD} 3.38\right.$ sign $\left.\mathrm{km}^{-1}\right)$ than in secondary forest $\left(0.31 \pm \mathrm{SD} 0.8\right.$ sign km $\mathrm{km}^{-1}$, Fig. $5 \mathrm{a}, N=23, W=364.5, d=0.9$ [95.0\% CI $0.0,1.86], P=0.016)$ and significantly lower below $1000 \mathrm{~m}(0.98 \pm \mathrm{SD} 1.8$ sign $\mathrm{km}^{-1}$ ) than above $1000 \mathrm{~m}$ elevation (3.96 \pm SD 2.9 sign $\mathrm{km}^{-1}$, Fig. 5b, Wilcoxon rank-sum test: $N=23, W=18.5, d=1.4$ [95.0\% CI 0.14, 3.01], $P=0.025)$. The mean encounter rate of chimpanzee signs did not differ significantly between 
Table I Density estimates for chimpanzees in Kom-Wum Forest Reserve, Cameroon, using three methods (May 15-September 23, 2018)

\begin{tabular}{llll}
\hline Parameters & Distance sampling & Marked nest count & Standing crop nest count \\
\hline Number of nests & 158 & 113 & 271 \\
Distance $(\mathrm{km})$ & 46 & 130 & 150 \\
Strip width $(\mathrm{km})$ & 0.02 & 0.02 & 0.02 \\
Decay time/intersurvey period (days)a & 101 & 64 & 101 \\
Proportion of nest buildersa & $\mathrm{NA}$ & 0.83 & 0.83 \\
Nest density (km $\left.{ }^{-2}\right)$ & 80.4 & 24.9 & 43.9 \\
Chimpanzee density $\left(\mathrm{km}^{-2}\right)$ & 0.94 & 0.37 & 0.48 \\
Chimpanzee & 83 & 37 & 46 \\
\hline
\end{tabular}

a Proportion of nest builders in the population from Plumptre and Cox (2006) and nest construction rate per day from Plumptre and Reynolds (1996).

areas outside $\left(3.31 \pm \mathrm{SD} 3.0\right.$ sign $\left.\mathrm{km}^{-1}\right)$ and inside the reserve boundaries $(1.08$ $\pm \mathrm{SD} 1.8$ sign $\mathrm{km}^{-1}$, Fig. 5c, Wilcoxon rank-sum test: $N=23, W=28.5, d=$ $-0.97[95.0 \% \mathrm{CI}-2.37,0.13], P=0.060)$.
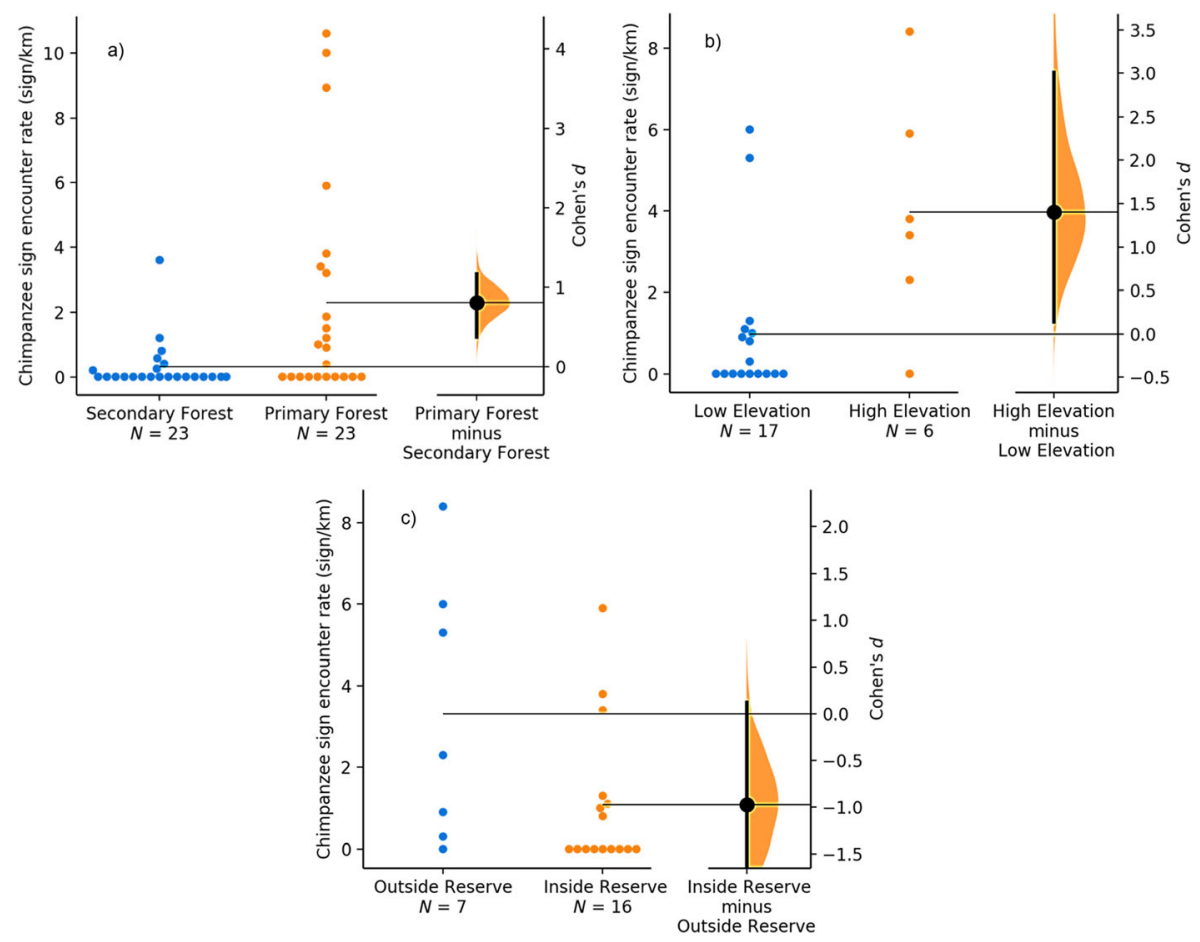

Fig. 5 Gardner-Altman estimation plots for mean encounter rates of chimpanzee signs in (a) secondary and mature forest, (b) low and high elevation, and (c) outside and inside Kom-Wum Forest Reserve, Cameroon (May 15-September 23, 2018). In each panel, empirical data for both groups are plotted on the left axis; mean Cohen's $d$ is represented as a dot and horizontal line on the right axis; vertical error bars represent bootstrap 95\% confidence interval together with the resampling distribution from 5000 resamples. 
Encounter Rates of Human Signs Overall, we encountered 271 human signs along the 23 transects. Hunting $(N=142)$ was the most common sign, followed by farming $(N=$ $52)$, logging $(N=41)$, grazing $(N=22)$, and collection of nontimber forest products $(N$ =14). The encounter rate of human activities was 1.81 signs km$~^{-1}$. Common signs of hunting included snares, cartridge cases, hunting camps, and traps. The mean encounter rate of human signs was significantly lower in mature $\left(0.94 \pm\right.$ SD 2.14 sign km$\left.~^{-1}\right)$ than in secondary forest $\left(8.02 \pm \mathrm{SD} 13.55\right.$ sign km${ }^{-1}$, Fig. 6a, Wilcoxon rank-sum test: $N=$ 23, $W=358, d=-7.09$ [95.0\% CI $-15.3,-3.2], P=0.029)$. The mean encounter rates of human signs did not differ significantly between elevations (above $1000 \mathrm{~m}: 1.4 \pm \mathrm{SD}$ 1.61 signs km ${ }^{-1}$; below 1000 m: $5.58 \pm \mathrm{SD} 5.39$ signs km${ }^{-1}$, Fig. 6b, Wilcoxon ranksum test: $N=23, W=27.5, d=-0.901$ [95.0\% CI $-1.53,-0.364], P=0.204$ ) or

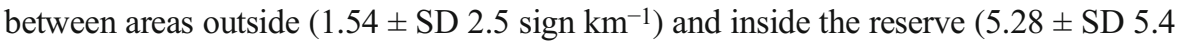
sign $\mathrm{km}^{-1}$, Fig. 6c, Wilcoxon rank-sum test: $N=23, W=80, d=0.79[95.0 \% \mathrm{CI}$ $0.0732,1.38], P=0.057)$.

Human activity significantly affected the encounter rate of chimpanzee signs $(N=$ 23, $R^{2}=0.21, \mathrm{df}=20, d=-0.65$ [95.0\% CI $\left.\left.-1.15,-0.07\right], P=0.036\right)$. Hunting had a significant negative effect on the encounter rate for signs of chimpanzees, while harvesting of nontimber forest products had no significant effect (Table II). The occurrence of chimpanzee signs was negatively related to secondary forest $(P<$ $0.001)$, habitat perforation $(P<0.001)$, and the edge length $(P<0.001)$ and positively related to core areas $(P<0.001)$.

\section{Discussion}

We estimated 10 (direct observation) to 83 (distance sampling) chimpanzees in the study area using the different methods. Signs of chimpanzee activity were significantly more common in mature forests than in secondary forest and at an elevation $>1000 \mathrm{~m}$ than at $<1000 \mathrm{~m}$. The frequency of chimpanzee signs decreased with increasing human activity, particularly hunting. Secondary forest cover, habitat perforation, and edge length negatively affected the occurrence of chimpanzee signs while core area had a positive effect. Using several methods to estimate chimpanzee density facilitated the assessment of the state of chimpanzee populations. The results are alarming, as most density estimates from this study are the lowest in the published literature (Table III; with the exception of distance sampling). This estimate of the population size of the chimpanzees in Kom-Wum Forest Reserve, coupled with previous integrated assessments in Ngel Nyaki Forest Reserve in Nigeria (Dutton 2012), highlight the urgent need to take action to conserve this subspecies in fragmented habitats.

\section{Chimpanzee Density}

In contrast to the five chimpanzee groups seen during the present study, previous surveys encountered one or two groups in Kom-Wum Forest Reserve (Chuo et al. 2017; Doumbé 2015). Our sampling effort (150 km) was higher than in previous surveys $(46 \mathrm{~km})$, but our encounter rate of chimpanzee groups $\left(0.03\right.$ groups km $\left.\mathrm{km}^{-1}\right)$ was similar to that in previous studies $\left(0.02\right.$ groups $\left.\mathrm{km}^{-1}\right)$. This suggests that the group 


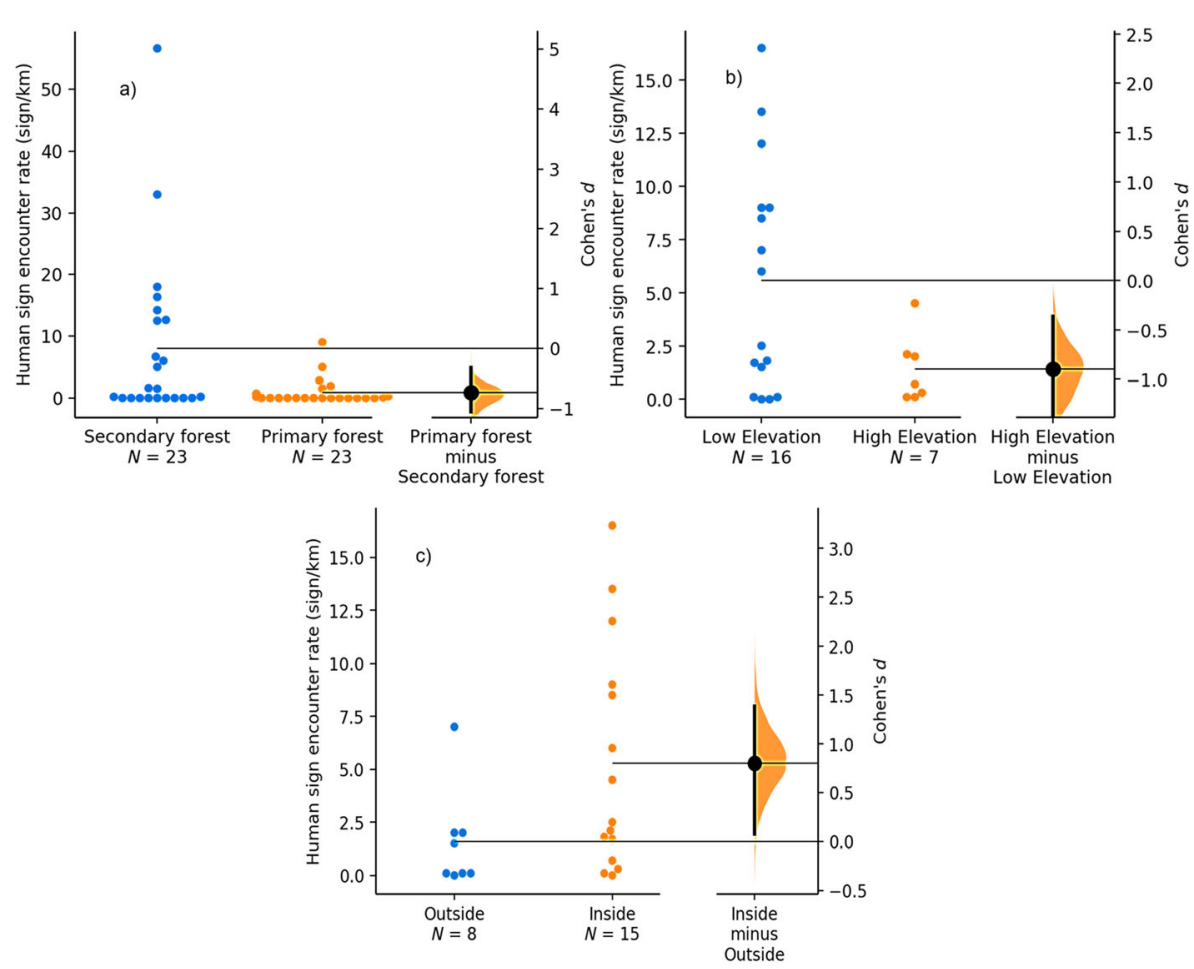

Fig. 6 Gardner-Altman estimation plots of mean encounter rates of human signs in (a) secondary and mature forest, (b) low and high elevation, and (c) outside and inside Kom-Wum Forest Reserve, Cameroon (May 15September 23, 2018). In each panel, empirical data for both groups are plotted on the left axis; mean Cohen's $d$ is represented as a dot and horizontal line on the right axis; vertical error bars represent bootstrap $95 \%$ confidence interval together with the resampling distribution from 5000 resamples.

sizes of chimpanzees observed directly are similar across studies and that the population may be stable since the first survey in 2015. Sampling effort could therefore be reduced in future studies.

The number of independent photographs captured by camera traps $(N=9)$ was higher than the number of direct observations of chimpanzees $(N=5)$. We could also identify the sex of a few chimpanzee individuals from camera trap footage. The relative abundance of chimpanzees estimated in our study was close to estimates for the central chimpanzee (Pan troglodytes troglodytes) in the northern sector of Dja Faunal Reserve in Cameroon (Bruce et al. 2018). A similarity in the habitat of both reserves (rainforest) can explain the closeness of these results: lowland montane rainforest for Kom-Wum

Table II Estimated coefficients and standard errors for a model using human activity signs to predict chimpanzee activity in Kom-Wum Forest Reserve, Cameroon (May 15- September 23, 2018)

\begin{tabular}{lllll}
\hline Coefficients & Estimate & Standard error & $t$ & $P$ \\
\hline (Intercept) & 3.00 & 0.64 & 4.69 & $<0.001$ \\
Hunting & -0.56 & 0.24 & -2.29 & 0.033 \\
Nontimber forest product collection & -0.65 & 0.80 & -0.81 & 0.425 \\
\hline
\end{tabular}


Table III Densities of chimpanzees across study sites (May 15 to September 23, 2018, for this study only)

\begin{tabular}{llllll}
\hline Study site & Country & $\begin{array}{l}\text { Decay } \\
\text { rates (days) }\end{array}$ & Method & $\begin{array}{l}\text { Density } \\
\left(\mathrm{km}^{-2}, \mathrm{RAI}\right) \pm 95 \% \mathrm{CI}\end{array}$ & Reference \\
\hline KWFR & Cameroon & - & $\mathrm{CT}$ & 1.43 & This study \\
DFR & Cameroon & - & $\mathrm{CT}$ & $1.61(0.77-2.9)$ & Bruce et al. (2018) \\
KWFR & Cameroon & - & DO & 0.12 & This study \\
GGNP & Nigeria & - & DO & 1.3 & Sommer et al. (2004) \\
NNFR & Nigeria & - & DO & 1.5 & Dutton (2012) \\
KWFR & Cameroon & 101 & DS & $0.94(0.50-1.77)$ & This study \\
NNFR & Nigeria & 168.48 & DS & 0.33 & Dutton (2012) \\
KWFR & Cameroon & - & MNC & 0.37 & This study \\
NNFR & Nigeria & - & MNC & 1.67 & Beck and Chapman (2008) \\
NNFR & Nigeria & - & MNC & 0.69 & Dutton (2012) \\
KWFR & Cameroon & 101 & SCNC & 0.48 & This study \\
MDNP & Cameroon & 88 & SCNC & $0.88(0.55-1.41)$ & Kamgang et al. (2018) \\
NNFR & Nigeria & 168.48 & SCNC & 1.5 & Dutton (2012) \\
\hline
\end{tabular}

Camera trapping, Direct observation, Distance sampling, Dja Faunal Reserve, Kom-Wum Forest Reserve, Gashaka-Gumti National Park, Mbam Djerem National Park, Ngel Nyaki Forest Reserve

Forest Reserve (Sunderland and Mannaseh 2003) and lowland rainforest for Dja Faunal Reserve (Abwe et al. 2019; Sesink Clee et al. 2015).

Estimates of nest decay time needed for additional density methods indicated 101 days for total decay, which is lower than estimates from Ngel Nyaki Forest Reserve in Nigeria (Dutton 2012). Ground nests decayed considerably faster than arboreal nests. Ground nests are often poorly constructed, since they are usually used temporarily during the day for resting (Brownlow et al. 2001; Koops et al. 2007). Site-specific differences are not surprising given that nest decay times vary over space and time and with sample period, tree species, forest type, nest height and position, soil $\mathrm{pH}$, and average rainfall (Ancrenaz et al. 2004; Buij et al. 2003; Johnson et al. 2005; Kouakou et al. 2009; Marshall et al. 2007; Mathewson et al. 2008; van Schaik et al. 1995; Walsh and White 2005).

The density estimate for chimpanzees based on distance sampling was the only estimate that was higher than previously derived densities for chimpanzees (Kamgang et al. 2018). Density estimates based on the SCNC and MNC methods were lower than all previously published results. The higher densities of chimpanzees in Ngel Nyaki Forest Reserve could be a result of the reserve's small size $\left(7 \mathrm{~km}^{2}\right)($ Beck and Chapman 2008; Dutton 2012) compared to Kom-Wum Forest Reserve $\left(80 \mathrm{~km}^{2}\right)$. The higher estimated densities for the Western chimpanzee (Pan troglodytes verus) in Taï National Park is probably due to the presence of large undisturbed remnants of primary tropical forest (Boesch and Boesch-Achermann 2000; Kouakou et al. 2009). Generally, density estimates of 0.1-0.9 chimpanzee $\mathrm{km}^{-2}$ in this study fall within the ranges for sites of central chimpanzees in Cameroon (0.1-1.2 km-2) (Ngalla et al. 2005) and of other populations of chimpanzees across West Africa $\left(0.2-2.0 \mathrm{~km}^{-2}\right)$ (Kormos et al. 2003). 
Nest decay time and season may have influenced the results of the SCNC $(0.5$ chimpanzee $\mathrm{km}^{-2}, 43$ individuals $)$ and distance sampling approaches ( 0.9 chimpanzee $\mathrm{km}^{-2}, 83$ individuals) as both rely on nest decay time to estimate chimpanzee density (Mathewson et al. 2008; Tutin et al. 1995). The result of the MNC technique (0.4 chimpanzee $\mathrm{km}^{-2}, 37$ individuals) was comparable to the 10 chimpanzees directly observed and the largest nest group size (22 nests) encountered during our survey. Subsequent surveys in Kom-Wum Forest Reserve should consider using the MNC technique, since it is not biased by estimated nest decay rates and is sensitive in detecting changes in density, movement, and seasonal habitat use (Buij et al. 2003; Devos et al. 2008). The survey period should include data from the dry season for SCNC and distance sampling methods to accurately estimate average nest decay times in the dry season. The SCNC method is cheaper, requires less labour, and will produce accurate estimates if the nest decay time is properly calculated (Kouakou et al. 2009). However, other parameters such as elevation, wood density, and soil $\mathrm{pH}$ should be considered when employing the SCNC method (Buij et al. 2003; van Schaik et al. 1995). Each method has strengths and weaknesses and is applicable under certain conditions (Vink et al. 2020). Overall, 10-83 chimpanzees live in the study area depending on the estimation method.

\section{Chimpanzee Activity}

The observed encounter rate for chimpanzee signs (2.7 signs $\left.\mathrm{km}^{-1}\right)$ was considerably lower than rates previously reported for this study area (Chuo et al. 2017), but there were differences in activity signs between habitat types. We found higher encounter rates in mature forest at higher elevation. At Tofala Hill Wildlife Sanctuary, chimpanzees also nest more frequently in mature vegetation at higher elevations (800-1000 m; Njukang et al. 2019). At BabankiFinge forest in Cameroon, a majority of nests were recorded in dense vegetation at 500-2300 m (Doumbé 2014). At Mbam and Djerem National Park in Cameroon, chimpanzees preferred dense habitats at higher elevation (Kamgang et al. 2018). Similar results were recorded from Seringbara, Nimba Mountains in the Republic of Guinea, where chimpanzee nests were more abundant in mature forest and above $1000 \mathrm{~m}$ than in secondary forest and below $1000 \mathrm{~m}$ (Koops et al. 2012). More recent research in the Nimba Mountains revealed that chimpanzees preferred old-growth over secondary forest for nesting (Granier et al. 2014). Higher encounter rates of human activity in the secondary forests in KomWum Forest Reserve may be linked to the low encounter rates for chimpanzee signs compared to those in mature forest areas. Higher encounter rates for chimpanzee signs in mature forests in Tofala Hill Wildlife Sanctuary and Babanki-Finge Forest in Cameroon were also associated with lower encounter rates for hunting, logging, and farming. A review of 52 chimpanzee nest surveys across West Africa showed that chimpanzees prefer rainforests with a low degree of human impact (Heinicke et al. 2019). In the southeastern forest region of Bossou, Guinea, chimpanzees preferred mature forest with abundant supply of wild fruits over disturbed habitats for traveling and resting (Bryson-Morrison et al. 2017). Similarly to other chimpanzee subspecies, the chimpanzees of KomWum prefer mature forest compared to secondary forest. Primary forest tend to 
provide suitable conditions (habitat with enough food and shelter) for the Nigeria-Cameroon chimpanzee (Carvalho et al. 2020) and other great apes species (Junker et al. 2012).

After controlling for the effect of forest cover, habitat perforation, edge length, and secondary forest had a significant negative effect on chimpanzee occurrence in KomWum Forest Reserve. In contrast, core areas had a significant positive effect. The low occurrence of chimpanzees in perforated forest, at forest edges, and in secondary forest is probably best explained by higher human activity in these areas, as previously reported (Morgan et al. 2011). This interpretation is supported by results from Guinea, where chimpanzees were more likely to feed away from cultivated areas than away from mature forest (Bryson-Morrison et al. 2017). Other primates respond negatively to habitat degradation (Arroyo-Rodríguez and Dias 2010). For example, in Los Tuxtlas and the lowlands of Tabasco, Mexico, the mantled howler (Alouatta palliata) prefered interior forest with high-quality habitat (feeding trees with larger diameter at breast height) to edge forest (Arroyo-Rodriguez and Mandujano 2006; Muñoz et al. 2006). Although we did not assess food availability of chimpanzees in forest edges and interior forest in this study, the positive relationship between chimpanzee occurrence and core areas in Kom-Wum Forest Reserve could be explained by resource availability (e.g., food and nest sites). At Goualougo Triangle in the Republic of Congo, transects that traversed the core area of the community range had higher encounter rates of chimpanzee nests and nests sites compared to more peripheral areas (Morgan et al. 2006).

The results we obtained for Kom-Wum Forest Reserve contrast with those from Nyungwe National Park, Rwanda, where chimpanzees used forest edges for feeding, nesting, and traveling (Hasabwamariya 2018). This difference may be a consequence of the behavioral flexibility of primates living in human-dominated landscape (McCarthy et al. 2017). The persistence of primates in human disturbed landscapes can be related to their flexibility in diet selection (Marsh et al. 2016). For example, in Magdalena Valley, Colombia, white-fronted capuchins (Cebus albifrons) (a more diet generalist species) were encountered in a majority of fragments irrespective of high human disturbance. In contrast, the brown spider monkey (Ateles hybridus) (a species with a more selective diet) was absent or less abundant in highly disturbed forest fragments. At La Suerte Biological Research Station, Costa Rica, there was no difference in the encounter rates of mantled howler (Alouatta palliata), white-faced capuchins (Cebus capucinus), and Central American spider monkeys (Ateles geoffroyi) in forest edges with high human disturbance and interior forest (Bolt et al. 2018).

\section{Conclusion}

This study shows that forest degradation resulting from human activity had a significant negative impact on the encounter rate of chimpanzee signs in Kom-Wum Forest Reserve, Cameroon. Chimpanzee signs were mostly found in mature forest compared to secondary forest, at higher elevation than lower elevation, and were less frequently observed with increasing human activities. This study supports previous work showing that sampling effort and methodological approach can yield variable estimates of population size (Vink et al. 2020). The MNC technique is sensitive in detecting 
changes in density (Buij et al. 2003; Devos et al. 2008) and is therefore recommended in combination with camera trapping to monitor the population status of chimpanzees. Our results reveal the importance of undisturbed mature forests as core habitats for chimpanzee populations in Kom-Wum Forest Reserve and surrounding forests. Secondary forests may provide essential habitats for chimpanzees (Basabose 2005), but chimpanzees in this study tended to avoid secondary forest, most likely due to high human activity. Future effort focusing on the conservation of chimpanzees in KomWum Forest Reserve should be directed toward reducing human activities and reforestating degraded areas. Local human communities need to be actively involved in monitoring programs and law enforcement activities, such as regular antipoaching patrols within and around the reserve, to prevent hunting. Providing incentives to local community members to generate alternative livelihood activities such as piggeries and poultry farms has the potential to reduce the pressure on forest resources (Van Vliet 2011). The promotion of conservation education is essential to discourage bushmeat hunting and to maintain continuous forest through the reforestation of degraded areas.

Supplementary Information The online version contains supplementary material available at https://doi.org/ 10.1007/s10764-020-00191-2.

Acknowledgments This research was supported by the International Foundation for Science, Stockholm, Sweden, the Organisation of Islamic Cooperation's Standing Committee on Scientific and Technological Cooperation (COMSTECH), and the Rufford Foundation through grants to C. Fotang. We thank the field assistants, Mr. Akou Emmanuel Mbeng and Ambe Godwill Akou, for their assistance in data collection. We thank Dr. Serge Alexis Kamgang, Mr. Yisa Ginath Yuh, and Mr. Ejike Richard Ugba for their assistance in data analyses. We acknowledge the contribution of Prof. Mary Katherine Gonder, Dr. Eileen Bogweh Nchanji, Mr. Kenneth KumechaTah, Osiris Doumbé, Dr. Mercy Nambu Diangha, and Dr. Mvo Denis Chou for their helpful comments and contributions to an earlier version of the manuscript. We are grateful to Prof. Manfred Wanner, Dr. Birte Seffert, and Dr. Enrique Garcia de la Riva for their invaluable support and guidance as well as the technical staff of the Department of Ecology BTU Cottbus-Senftenberg for logistic support. We thank the editors (Prof. Joanna Setchell, Dr. Songtao Guo) and two anonymous reviewers for their valuable comments on the manuscript.

Author contributions CF, CR, EEA, KB, PS, TEA, and UB conceived and designed the experiments; CF conducted fieldwork; $\mathrm{CF}$ and PD developed methodology; $\mathrm{CF}, \mathrm{ECE}$, and $\mathrm{KB}$ performed statistical analyses; and $\mathrm{CF}$ and $\mathrm{KB}$ wrote the manuscript.

Funding Open Access funding enabled and organized by Projekt DEAL.

Open Access This article is licensed under a Creative Commons Attribution 4.0 International License, which permits use, sharing, adaptation, distribution and reproduction in any medium or format, as long as you give appropriate credit to the original author(s) and the source, provide a link to the Creative Commons licence, and indicate if changes were made. The images or other third party material in this article are included in the article's Creative Commons licence, unless indicated otherwise in a credit line to the material. If material is not included in the article's Creative Commons licence and your intended use is not permitted by statutory regulation or exceeds the permitted use, you will need to obtain permission directly from the copyright holder. To view a copy of this licence, visit http://creativecommons.org/licenses/by/4.0/. 


\section{References}

Abwe, E. E., \& Morgan, B. J. (2008). The Ebo forest: Four years of preliminary research and conservation of the Nigeria-Cameroon chimpanzee (Pan troglodytes vellerosus). Pan Africa News, 15(2), 26-29.

Abwe, E. E., Morgan, B. J., Doudja, R., Kentatchime, F., Mba, F., et al (2020). Dietary ecology of the NigeriaCameroon chimpanzee (Pan troglodytes ellioti). International Journal of Primatology, 41(1), 81-104. https://doi.org/10.1007/s10764-020-00138-7.

Abwe, E. E., Morgan, B. J., Tchiengue, B., Kentatchime, F., Doudja, R., et al (2019). Habitat differentiation among three Nigeria-Cameroon chimpanzee (Pan troglodytes ellioti) populations. Ecology and Evolution, 9(3), 1489-1500. https://doi.org/10.1002/ece3.4871.

Ancrenaz, M., Gimenez, O., Ambu, L., Ancrenaz, K., Andau, P., et al (2004). Aerial surveys give new estimates for orangutans in Sabah, Malaysia. PLoS Biology, 3(1), e3. https://doi.org/10.1371/journal. pbio.0030003.

Arroyo-Rodríguez, V., \& Dias, P. A. D. (2010). Effects of habitat fragmentation and disturbance on howler monkeys: A review. American Journal of Primatology, 72(1), 1-16. https://doi.org/10.1002/ajp.20753.

Arroyo-Rodríguez, V., \& Mandujano, S. (2006). Forest fragmentation modifies habitat quality for Alouatta palliata. International Journal of Primatology, 27(4), 1079-1096. https://doi.org/10.1007/s10764-0069061-0.

Baayen, R. H., Davidson, D. J., \& Bates, D. M. (2008). Mixed-effects modeling with crossed random effects for subjects and items. Journal of Memory and Language, 59(4), 390-412. https://doi.org/10.1016/j.jml. 2007.12.005.

Basabose, A. K. (2005). Ranging patterns of chimpanzees in a montane forest of Kahuzi, Democratic Republic of Congo. International Journal of Primatology, 26(1), 33. https://doi.org/10.1007/s10764-005-0722-1.

Beck, J., \& Chapman, H. (2008). A population estimate of the endangered chimpanzee Pan troglodytes vellerosus in a Nigerian montane forest: Implications for conservation. Oryx, 42(3), 448-451. https://doi. org/10.1017/S0030605308001397.

Boesch, C. (1995). Innovation in wild chimpanzees (Pan troglodytes). International Journal of Primatology, 16(1), 1-16. https://doi.org/10.1007/BF02700150.

Boesch, C., \& Boesch-Achermann, H. (2000). The chimpanzees of the Täi Forest: Behavioural ecology and evolution. New York: Oxford University Press.

Bolt, L. M., Schreier, A. L., Voss, K. A., Sheehan, E. A., Barrickman, N. L., et al (2018). The influence of anthropogenic edge effects on primate populations and their habitat in a fragmented rainforest in Costa Rica. Primates, 59(3), 301-311. https://doi.org/10.1007/s10329-018-0652-0.

Brownlow, A. R., Plumptre, A. J., Reynolds, V., \& Ward, R. (2001). Sources of variation in the nesting behavior of chimpanzees (Pan troglodytes schweinfurthii) in the Budongo Forest, Uganda. American Journal of Primatology, 55(1), 49-55. https://doi.org/10.1002/ajp.1038.

Bruce, T., Amin, R., Wacher, T., Fankem, O., Ndjassi, C., et al (2018). Using camera trap data to characterize terrestrial larger-bodied mammal communities in different management sectors of the Dja Faunal Reserve, Cameroon. African Journal of Ecology, 56(4), 759-776. https://doi.org/10.1111/aje.12574.

Bryson-Morrison, N., Tzanopoulos, J., Matsuzawa, T., \& Humle, T. (2017). Activity and habitat use of chimpanzees (Pan troglodytes verus) in the anthropogenic landscape of Bossou, Guinea, West Africa. International Journal of Primatology, 38(2), 282-302. https://doi.org/10.1007/s10764-016-9947-4.

Buckland, S. T., Anderson, D. R., Burnham, K. P., Laake, J. L., Borchers, D. L., \& Thomas, L. (2001). Introduction to distance sampling estimating abundance of biological populations. Oxford: Oxford University Press.

Buij, R., Singleton, I., Krakauer, E., \& van Schaik, C. P. (2003). Rapid assessment of orangutan density. Biological Conservation, 114(1), 103-113. https://doi.org/10.1016/S0006-3207(03)00015-6.

Carvalho, J., Graham, B., Bocksberger, G., Maisels, F., Williamson, E. A., Wich, S., et al. (2020). Predicting range shifts of African apes under global change scenarios. BioRxiv. https://doi.org/10.1101/2020.06.25. 168815.

Chapman, C. A., \& Peres, C. A. (2001). Primate conservation in the new millennium: the role of scientists. Evolutionary Anthropology: Issues, News, and Reviews, 10(1), 16-33. https://doi.org/10.1002/15206505(2001)10:1<16::AID-EVAN1010>3.0.CO;2-O.

Chuo, M. D., Tsi, E. A., Chefor, F., \& Fru, B. S. (2017). Estimation of chimpanzee's (Pan troglodytes ellioti) abundance in the Kimbi-Fungum National Park and Kom-Wum Forest Reserve, Nw, Cameroon. Journal of Biodiversity Management \& Forestry, 6, 3. https://doi.org/10.4172/2327-4417.1000185.

Congalton, R. G. (1991). A review of assessing the accuracy of classifications of remotely sensed data. Remote Sensing of Environment, 37(1), 35-46. https://doi.org/10.1016/0034-4257(91)90048-B. 
Curtis, P. G., Slay, C. M., Harris, N. L., Tyukavina, A., \& Hansen, M. C. (2018). Classifying drivers of global forest loss. Science, 361(6407), 1108-1111. https://doi.org/10.1126/science.aau3445.

Devos, C., Sanz, C., Morgan, D., Onononga, J.-R., Laporte, N., \& Huynen, M.-C. (2008). Comparing ape densities and habitats in northern Congo: Surveys of sympatric gorillas and chimpanzees in the Odzala and Ndoki regions. American Journal of Primatology, 70(5), 439-451. https://doi.org/10.1002/ajp.20514.

Doumbé, O. A. (2014). Habitat mapping of the Babanki-Finge Forest, and survey on the rarest chimpanzee (Pan troglodytes ellioti) in the Bamenda Highlands, North-West Cameroon. Master's thesis, The University of Roehampton, London.

Doumbé, O. A. (2015). Conservation of the Nigeria-Cameroon chimpanzee (Pan troglodytes ellioti) in the Northwest Region of Cameroon. https://www.rufford.org/projects/osiris_doumbe. Accessed 18 Oct 2019.

Dutton, P., \& Chapman, H. (2015a). Dietary preferences of a submontane population of the rare NigerianCameroon chimpanzee (Pan troglodytes ellioti) in Ngel Nyaki Forest Reserve, Nigeria. American Journal of Primatology, 77(1), 86-97. https://doi.org/10.1002/ajp.22313.

Dutton, P., \& Chapman, H. (2015b). New tools suggest local variation in tool use by a montane community of the rare Nigeria-Cameroon chimpanzee, Pan troglodytes ellioti, in Nigeria. Primates, 56(1), 89-100. https://doi.org/10.1007/s10329-014-0451-1.

Dutton, P., Moltchanova, E., \& Chapman, H. (2016). Nesting ecology of a small montane population of the Nigerian/Cameroon chimpanzee (Pan troglodytes ellioti) in Nigeria. Folia Primatologica, 87(6), 361374. https://doi.org/10.1159/000454921.

Dutton, P. E. (2012). Chimpanzee (Pan troglodytes ellioti) ecology in a Nigerian montane forest. PhD thesis, Biological Sciences, University of Canterbury, New Zealand.

Enoguanbhor, E. C., Gollnow, F., Nielsen, J. O., Lakes, T., \& Walker, B. B. (2019). Land cover change in the Abuja City-Region, Nigeria: Integrating GIS and remotely sensed data to support land use planning. Sustainability, 11(5), 1313. https://doi.org/10.3390/su11051313.

Estrada, A., \& Coates-Estrada, R. (1996). Tropical rain forest fragmentation and wild populations of primates at Los Tuxtlas, Mexico. International Journal of Primatology, 17(5), 759-783. https://doi.org/10.1007/ BF02735263.

Estrada, A., Anzures D, A., \& Coates-Estrada, R. (1999). Tropical rain forest fragmentation, howler monkeys (Alouatta palliata), and dung beetles at Los Tuxtlas, Mexico. American Journal of Primatology, 48(4), 253-262. https://doi.org/10.1002/(SICI)1098-2345(1999)48:4<253::AID-AJP1>3.0.CO;2-D.

Estrada, A., Garber, P. A., \& Chaudhary, A. (2019). Expanding global commodities trade and consumption place the world's primates at risk of extinction. PeerJ, 7, e7068. https://doi.org/10.7717/peerj.7068.

Estrada, A., Garber, P. A., Rylands, A. B., Roos, C., Fernandez-Duque, E., et al (2017). Impending extinction crisis of the world's primates: Why primates matter. Science Advances, 3(1), e1600946. https://doi.org/10. 1126/sciadv.1600946.

Fahrig, L. (2003). Effects of habitat fragmentation on biodiversity. Annual Review of Ecology, Evolution, and Systematics, 34(1), 487-515. https://doi.org/10.1146/annurev.ecolsys.34.011802.132419.

Fotang, C. (2018). Ecology and behaviour of the Nigeria-Cameroon Chimpanzee in Kom-Wum Forest Reserve and Mbi Crater Kefem Landscape in the North-West Region of Cameroon. https://www. rufford.org/projects/chefor fotang. Accessed 29 Oct 2019.

Fowler, A., \& Sommer, V. (2007). Subsistence technology of Nigerian chimpanzees. International Journal of Primatology, 28(5), 997-1023. https://doi.org/10.1007/s10764-007-9166-0.

Fruth, B., \& Hohmann, G. (1996). Nest building behavior in the great apes: The great leap forward? In W. C. MGrew, L. F. Marchant, \& T. Nishida (Eds.), Great ape societies (pp. 225-240). Cambridge: Cambridge University Press.

Funwi-Gabga, N., Kuehl, H., Maisels, F., Cheyne, S. M., Wich, S. A., et al (2014). The status of apes across Africa and Asia. In H. Rainer, A. White, \& A. Lanjouw (Eds.), State of the apes 2013: Extractive industries and ape conservation (pp. 253-277). Cambridge: Cambridge University Press.

Furuichi, T., \& Hashimoto, C. (2000). Ground beds of chimpanzees in the Kalinzu Forest, Uganda. Pan Africa News, 7(2), 26-28.

Ganasri, B. P., \& Dwarakish, G. S. (2015). Study of land use/land cover dynamics through classification algorithms for Harangi catchment area, Karnataka State, INDIA. Aquatic Procedia, 4, 1413-1420. https:// doi.org/10.1016/j.aqpro.2015.02.183.

Ghiglieri, M. P. (1984). Feeding ecology and sociality of chimpanzees in the Kibale Forest, Uganda. In P. S. Rodman \& J. G. H. Cant (Eds.), Adaptations for foraging in non-human primates (pp. 161-194). New York: Columbia University Press.

Gonder, M. K., Oates, J. F., Disotell, T. R., Forstner, M. R. J., Morales, J. C., \& Melnick, D. J. (1997). A new west African chimpanzee subspecies? Nature, 388(6640), 337. https://doi.org/10.1038/41005. 
González-Solís, J., Guix, J. C., Mateos, E., \& Llorens, L. (2001). Population density of primates in a large fragment of the Brazilian Atlantic rainforest. Biodiversity \& Conservation, 10(8), 1267-1282. https://doi. org/10.1023/A:1016678126099.

Granier, N., Hambuckers, A., Matsuzawa, T., \& Huynen, M.-C. (2014). Density estimates and nesting-site selection in chimpanzees of the Nimba Mountains, Côte d'Ivoire, and Guinea. American Journal of Primatology, 76(11), 999-1010. https://doi.org/10.1002/ajp.22278.

Greengrass, E. J., \& Maisels, F. (2007). Conservation of the Nigerian-Cameroon chimpanzee P. t. vellerosus (and other mammals) in and around the Banyang-Mbo Wildlife Sanctuary, South-west Province, Cameroon. Yaoundé, Cameroon: Wildlife Conservation Society.

Haddad, N. M., Brudvig, L. A., Clobert, J., Davies, K. F., Gonzalez, A., et al (2015). Habitat fragmentation and its lasting impact on Earth's ecosystems. Science Advances, 1(2), e1500052. https://doi.org/10.1126/ sciadv. 1500052 .

Hasabwamariya, E. (2018). Influences of forest edges and human activities on the dry season ranging patterns of chimpanzees (Pan troglodytes schweinfurthii) in Nyungwe National Park, Rwanda. Master's thesis, Antioch University, New England, Yellow Springs, OH.

Hashimoto, C. (1995). Population census of the chimpanzees in the Kalinzu Forest, Uganda: Comparison between methods with nest counts. Primates, 36(4), 477-488. https://doi.org/10.1007/BF02382870.

Heinicke, S., Mundry, R., Boesch, C., Amarasekaran, B., Barrie, A., et al. (2019). Characteristics of positive deviants in western chimpanzee populations Frontiers in Ecology and Evolution, 7, 16. https://doi.org/10. 3389/fevo.2019.00016.

Ho, J., Tumkaya, T., Aryal, S., Choi, H., \& Claridge-Chang, A. (2019). Moving beyond P values: Data analysis with estimation graphics. Nature Methods, 16(7), 565-566. https://doi.org/10.1038/s41592-0190470-3.

Howe, E. J., Buckland, S. T., Després-Einspenner, M.-L., \& Kühl, H. S. (2017). Distance sampling with camera traps. Methods in Ecology and Evolution, 8(11), 1558-1565. https://doi.org/10.1111/2041-210X. 12790.

Hughes, N., Rosen, N., Gretsky, N., \& Sommer, V. (2011). Will the Nigeria-Cameroon chimpanzee go extinct? Models derived from intake rates of ape sanctuaries. In V. Sommer \& C. Ross (Eds.), Primates of Gashaka: Socioecology and conservation in Nigeria's biodiversity hotspot (pp. 493-523). New York: Springer Science+Business Media.

Humle, T., Maisels, F., Oates, J. F., Plumptre, A., \& Williamson, E. A. (2016). Pan troglodytes. The IUCN Red List of Threatened Species 2016. https://doi.org/10.2305/IUCN.UK.2016-2.RLTS. T15933A17964454.en. Accessed 11 Oct 2020.

Jenks, K. E., Chanteap, P., Kanda, D., Peter, C., Cutter, P., et al. (2011). Using relative abundance indices from camera-trapping to test wildlife conservation hypotheses: An example from Khao Yai National Park, Thailand. Tropical Conservation Science, 4(2), 113-131. https://doi.org/10.1177/194008291100400203.

Johnson, A. E., Knott, C. D., Pamungkas, B., Pasaribu, M., \& Marshall, A. J. (2005). A survey of the orangutan (Pongo pygmaeus wurmbii) population in and around Gunung Palung National Park, West Kalimantan, Indonesia based on nest counts. Biological Conservation, 121(4), 495-507. https://doi.org/ 10.1016/j.biocon.2004.06.002.

Junker, J., Blake, S., Boesch, C., Campbell, G., Du Toit, L., Duvall, C., et al. (2012). Recent decline in suitable environmental conditions for African great apes. Diversity and Distributions, 18(11), 1077-1091. https://oi.org/10.1111/ddi.12005.

Kah, H. (2015). "Wuai, Kesiazheh, Nyengui:” History and livelihood challenges in a Cameroon's montane forest reserve. Economic- and Ecohistory, 11(11), 93-104.

Kamgang, S. A., Bobo, K. S., Maisels, F., Ambahe, R. D. D., Ongono, D. E. A., et al (2018). The relationship between the abundance of the Nigeria-Cameroon chimpanzee (Pan troglodytes ellioti) and its habitat: A conservation concern in Mbam-Djerem National Park, Cameroon. BMC Ecology, 18(1), 40. https://doi. org/10.1186/s12898-018-0199-3.

Kim, S. (2019). Jeju Island climate modeling using multiple linear regression analysis. Journal of Analysis of Applied Mathematics, 13, 118-136.

Knight, A., Chapman, H. M., \& Hale, M. (2016). Habitat fragmentation and its implications for Endangered chimpanzee Pan troglodytes conservation. Oryx, 50(3), 533-536. https://doi.org/10.1017/ S0030605315000332. 
Koops, K., Humle, T., Sterck, E. H. M., \& Matsuzawa, T. (2007). Ground-nesting by the chimpanzees of the Nimba Mountains, Guinea: Environmentally or socially determined? American Journal of Primatology, 69(4), 407-419. https://doi.org/10.1002/ajp.20358.

Koops, K., McGrew, W. C., de Vries, H., \& Matsuzawa, T. (2012). Nest-building by chimpanzees (Pan troglodytes verus) at Seringbara, Nimba Mountains: Antipredation, thermoregulation, and antivector hypotheses. International Journal of Primatology, 33(2), 356-380. https://doi.org/10.1007/s10764-0129585-4.

Kormos, R., Boesch, C., Bakarr, M. I., \& Butynski, T. M. (2003). West African chimpanzees. Status survey and conservation action plan. Gland, Cambridge: IUCN/SSC Primate Specialist Group.

Kouakou, C. Y., Boesch, C., \& Kuehl, H. (2009). Estimating chimpanzee population size with nest counts: Validating methods in Taï National Park. American Journal of Primatology, 71(6), 447-457. https://doi. org/10.1002/ajp.20673.

Kühl, H., Maisels, F., Ancrenaz, M., \& Williamson, E. A. (2008). Best practice guidelines for the surveys and monitoring of great ape populations. Gland, Switzerland: IUCN/SSC Primate Specialist Group.

Last, C., \& Muh, B. (2013). Effects of human presence on chimpanzee nest location in the Lebialem Moné Forest landscape, south-west region, Cameroon. Folia Primatologica, 84(1), 51-63. https://doi.org/10. $1159 / 000346305$.

Maisels, F., Ambahe, E., Ambassa, R., Nvemgah Yara, C., \& Fosso, B. (2009). Great ape and human impact monitoring in the Mbam et Djerem National Park, Cameroon. In Final report to USFWS-GACF Agreement 98210-7-G290. New York: Wildlife Conservation Society.

Marsh, C., Link, A., King-Bailey, G., \& Donati, G. (2016). Effects of fragment and vegetation structure on the population abundance of Ateles hybridus, Alouatta seniculus and Cebus albifrons in Magdalena Valley, Colombia. Folia Primatologica, 87(1), 17-30. https://doi.org/10.1159/000443929.

Marshall, A. J., Salas, L. A., Stephens, S., Engström, L., Meijaard, E., \& Stanley, S. A. (2007). Use of limestone karst forests by Bornean orangutans (Pongo pygmaeus morio) in the Sangkulirang Peninsula, East Kalimantan, Indonesia. American Journal of Primatology, 69(2), 212-219. https://doi.org/10.1002/ ajp.20341.

Mathewson, P. D., Spehar, S. N., Meijaard, E., Sasmirul, A., \& Marshall, A. J. (2008). Evaluating orangutan census techniques using nest decay rates: Implications for population estimates. Ecological Applications, 18(1), 208-221. https://doi.org/10.1890/07-0385.1.

Mathot, L., \& Doucet, J. L. (2005). Wildlife surveys in rainforest concessions in order to identify protected areas. In M. De Dapper (Ed.), Tropical forest in a changing global context (pp. 241-254). Royal Academy of Overseas Sciences. Belgium: UNESCO.

McCarthy, M. S., Lester, J. D., \& Stanford, C. B. (2017). Chimpanzees (Pan troglodytes) flexibly use introduced species for nesting and bark feeding in a human-dominated habitat. International Journal of Primatology, 38(2), 321-337. https://doi.org/10.1007/s10764-016-9916-y.

McLennan, M. R., Spagnoletti, N., \& Hockings, K. J. (2017). The implications of primate behavioral flexibility for sustainable human-primate coexistence in anthropogenic habitats. International Journal of Primatology, 38(2), 105-121. https://doi.org/10.1007/s10764-017-9962-0.

McManus, E. (2005). Federal Republic of Nigeria. In J. Caldecott \& L. Miles (Eds.), World atlas of great apes and their conservation (pp. 378-383). Los Angeles: University of California Press.

Mitchell, M. W., Locatelli, S., Clee, P. R. S., Thomassen, H. A., \& Gonder, M. K. (2015). Environmental variation and rivers govern the structure of chimpanzee genetic diversity in a biodiversity hotspot. $B M C$ Evolutionary Biology, 15(1), 1-13. https://doi.org/10.1186/s12862-014-0274-0.

Morgan, B., Adeleke, A., Bassey, T., Bergl, R., Dunn, A., et al (2011). Regional action plan for the conservation of the Nigeria-Cameroon chimpanzee (Pan troglodytes ellioti). In Gland. Switzerland and San Diego, CA: IUCN/SSC Primate Specialist Group and Zoological Society of San Diego.

Morgan, D., Mundry, R., Sanz, C., Ayina, C. E., Strindberg, S., Lonsdorf, E., \& Kühl, H. S. (2018). African apes coexisting with logging: Comparing chimpanzee (Pan troglodytes troglodytes) and gorilla (Gorilla gorilla gorilla) resource needs and responses to forestry activities. Biological Conservation, 218, 277286. https://doi.org/10.1016/j.biocon.2017.10.026.

Morgan, D., Sanz, C., Onononga, J. R., \& Strindberg, S. (2006). Ape abundance and habitat use in the Goualougo Triangle, Republic of Congo. International Journal of Primatology, 27(1), 147-179. https:// doi.org/10.1007/s10764-005-9013-0. 
Muñoz, D., Estrada, A., Naranjo, E., \& Ochoa, S. (2006). Foraging ecology of howler monkeys in a cacao (Theobroma cacao) plantation in Comalcalco, Mexico. American Journal of Primatology, 68(2), 127142. https://doi.org/10.1002/ajp.20211.

Ndimbe, M. S., Morgan, B. J., Marino, J., \& Abwe, E. E. (2016). Population density estimate of the NigeriaCameroon chimpanzee (Pan troglodytes ellioti) in the Ebo forest. Cameroon: Unpublished report.

Ngalla, P.T., Miles, L. \& Caldecott, J. (2005). Republic of Cameroon. In J. Caldecott, \& L. Miles (Eds.), World atlas of great apes and their conservation (pp. 305-314). Los Angeles: University of California Press.

Njukang, A. P., Angwafor, T. E. I., Akwanjoh, S. R., Lebga, A. K., \& Chuo, M. D. O. (2019). Effects of anthropogenic activities on chimpanzee nest location in the Tofala Hill Wildlife Sanctuary (THWS), South West Region, Cameroon. International Journal of Forest, Animal and Fisheries Research, 3(1). https://doi.org/10.22161/ijfaf.3.6.1.

O’Brien, T. G., Kinnaird, M. F., \& Wibisono, H. T. (2003). Crouching tigers, hidden prey: Sumatran tiger and prey populations in a tropical forest landscape. Animal Conservation, 6(2), 131-139. https://doi.org/10. 1017/S1367943003003172.

Ogunjemite, B. G., \& Dansu, E. L. (2014). Relationship between anthropogenic activities and occurrence of the chimpanzees (Pan troglodytes) in Oluwa Forest Reserve, Nigeria. Ethiopian Journal of Environmental Studies and Management, 7(4), 402-410. https://doi.org/10.4314/ejesm.v7i4.7.

Plumptre, A. J., \& Cox, D. (2006). Counting primates for conservation: Primate surveys in Uganda. Primates, 47(1), 65-73. https://doi.org/10.1007/s10329-005-0146-8.

Plumptre, A. J., \& Reynolds, V. (1996). Censusing chimpanzees in the Budongo forest, Uganda. International Journal of Primatology, 17(1), 85-99. https://doi.org/10.1007/BF02696160.

PNDP (2011). National community driven development program, Wum council development plan. Bamenda: Republic of Cameroon https://www.pndp.org/documents/23_CDP_Wum.pdf. Accessed 29 Oct 2019.

Rovero, F., \& de Luca, D. W. (2007). Checklist of mammals of the Udzungwa Mountains of Tanzania. Mammalia, 71(1-2), 47-55. https://doi.org/10.1515/MAMM.2007.015.

Rovero, F., Tobler, M., \& Sanderson, J. (2010). Camera trapping for inventorying terrestrial vertebrates. In J. Eymann, J. Degreef, C. Hauser, J. C. Monje, Y. Samyn, \& D. Vandenspiegel (Eds.), Manual on field recording techniques and protocols for all taxa biodiversity inventories and monitoring (pp. 100-128). Brussels: The Belgian National Focal Point to the Global Taxonomy Initiative.

Sesink Clee, P. R., Abwe, E. E., Ambahe, R. D., Anthony, N. M., Fotso, R., et al (2015). Chimpanzee population structure in Cameroon and Nigeria is associated with habitat variation that may be lost under climate change. BMC Evolutionary Biology, 15(1), 2. https://doi.org/10.1186/s12862-014-0275-z.

Sommer, V., Adanu, J., Faucher, I., \& Fowler, A. (2004). Nigerian chimpanzees (Pan troglodytes vellerosus) at Gashaka: Two years of habituation efforts. Folia Primatologica, 75(5), 295-316. https://doi.org/10. $1159 / 000080208$.

Sunderland, T. C. H., \& Mannaseh, E. N. (2003). The Wildlife Conservation Society's Cameroon-Nigeria transboundary surveys project. Cameroon: Wildlife Conservation Society.

Thomas, L., Buckland, S. T., Rexstad, E. A., Laake, J. L., Strindberg, S., et al (2010). Distance software: Design and analysis of distance sampling surveys for estimating population size. Journal of Applied Ecology, 47(1), 5-14. https://doi.org/10.1111/j.1365-2664.2009.01737.x.

Tutin, C. E. G., \& Fernandez, M. (1984). Nationwide census of gorilla (Gorilla g. gorilla) and chimpanzee (Pan t. troglodytes) populations in Gabon. American Journal of Primatology, 6(4), 313-336. https://doi. org/10.1002/ajp.1350060403.

Tutin, C. E. G., Parnell, R. J., White, L. J. T., \& Fernandez, M. (1995). Nest building by lowland gorillas in the Lopé Reserve, Gabon: Environmental influences and implications for censusing. International Journal of Primatology, 16(1), 53. https://doi.org/10.1007/BF02700153.

Van Schaik, C. P., Priatna, A., \& Priatna, D. (1995). Population estimates and habitat preferences of orangutans based on line transects of nests. In R. D. Nadler, B. M. F. Galdikas, L. K. Sheeran, \& N. Rosen (Eds.), The neglected ape (pp. 129-147). New York: Plenum Press.

Van Vliet, N. (2011). Livelihood alternatives for the unsustainable use of bushmeat. Report prepared for the CBD Bushmeat Liaison Group. Technical Serices No. 60. In Montreal: Secretariat of the Convention on Biological Diversity.

Venables, W. N., Smith, D. M., \& Team, R. C. (2008). An introduction to R: Notes on R, a programming environment for data analysis and graphics. http://cran.r-project.org/doc/manuals/R-intro.pdf. Accessed 12 Oct 2020. 
Vink, D. N., Stewart, F. A., \& Piel, A. K. (2020). Comparing methods for assessing chimpanzee (Pan troglodytes schweinfurthii) party size: Observations, camera traps, and bed counts from a savannawoodland mosaic in the Issa Valley, Tanzania. International Journal of Primatology, 1-15. https://oi. org/10.1007/s10764-020-00142-x.

Vogt, P., Riitters, K. H., Estreguil, C., Kozak, J., Wade, T. G., \& Wickham, J. D. (2007). Mapping spatial patterns with morphological image processing. Landscape Ecology, 22(2), 171-177. https://doi.org/10. 1007/s10980-006-9013-2.

Walsh, P. D., Abernethy, K. A., Bermejo, M., Beyers, R., de Wachter, P., et al (2003). Catastrophic ape decline in western equatorial Africa. Nature, 422(6932), 611. https://doi.org/10.1038/nature01566.

Walsh, P. D., \& White, L. J. T. (2005). Evaluating the steady state assumption: Simulations of gorilla nest decay. Ecological Applications, 15(4), 1342-1350. https://doi.org/10.1890/03-5283.

White, L., \& Edwards, A. (2000). Conservation research in the African rainforests: A technical handbook. New York: Wildlife Conservation Society.

\section{Affiliations}

\section{Chefor Fotang ${ }^{1} \cdot$ Udo Bröring $^{1} \cdot$ Christian Roos $^{2} \cdot$ Evidence Chinedu $^{2}$ Enoguanbhor $^{3}$ - Ekwoge E. Abwe ${ }^{4,5} \cdot$ Paul Dutton $^{6}$ - Peter Schierack ${ }^{7}$ - Tsi Evaristus Angwafo ${ }^{8} \cdot$ Klaus Birkhofer $^{1}$}

Chefor Fotang

Chefor.Fotang@b-tu.de

1 Department of Ecology, Brandenburg University of Technology Cottbus-Senftenberg, Cottbus, Germany

2 German Primate Center, Gene Bank of Primates and Primate Genetics Laboratory, Leibniz Institute for Primate Research, Göttingen, Germany

3 Geoinformation Science Laboratory, Department of Geography, Humboldt University of Berlin, Berlin, Germany

4 Institute for Conservation Research, Zoological Society of San Diego, Escondido, CA 92027, USA

5 Ebo Forest Research Project, Messa, Yaoundé, Cameroon

6 Waikato Regional Council, Science and Strategy Directorate, Hamilton, New Zealand

7 Department of Multiparameter Diagnostics, Brandenburg University of Technology Cottbus-Senftenberg, Senftenberg, Germany

8 Faculty of Agronomy and Agricultural Sciences, University of Dschang, Dschang, Cameroon 